\title{
Décadrages Décadrages
}

cinéma, à travers champs Cinéma, à travers champs

$13 \mid 2008$

Anna Sanders Films, cinéma et art contemporain

\section{D'un espace l'autre : l'expropriation inexorable par la « délogeuse »}

Alain Boillat

\section{OpenEdition}

Journals

Édition électronique

URL : http://journals.openedition.org/decadrages/532

DOI : 10.4000/decadrages.532

ISSN : 2297-5977

Éditeur

Association Décadrages

Édition imprimée

Date de publication : 10 octobre 2008

Pagination : 106-108

ISBN : 978-2-9700582-8-1

ISSN : 2235-7823

Référence électronique

Alain Boillat, « D'un espace l'autre : l'expropriation inexorable par la « délogeuse » », Décadrages [En ligne], 13 | 2008, mis en ligne le 10 octobre 2009, consulté le 22 septembre 2020. URL : http://

journals.openedition.org/decadrages/532 ; DOI : https://doi.org/10.4000/decadrages.532

Ce document a été généré automatiquement le 22 septembre 2020.

( Décadrages 


\title{
D'un espace l'autre : l'expropriation inexorable par la « délogeuse »
}

\author{
Alain Boillat
}

Le court métrage de fiction La délogeuse qui a été gratifié à Locarno d'un « leopardino " est un film d'école - Julien Rouyet est étudiant à l'Ecole cantonale d'art de Lausanne dont l'ambition et la qualité dépassent l'exercice de style, le cinéaste jouant avec le caractère elliptique de la forme courte tout en lorgnant vers les possibilités narratives d'un long métrage qui sourdent avec une densité singulière dans les interstices de l'histoire racontée. Il est vrai que cette intrigue organisée autour de la prise de possession progressive par une subordonnée (une femme de ménage) de l'espace appartenant à ses employeurs ne nous est pas inconnue, bien qu'elle soit dépourvue ici - c'est même dans l'évidence avec laquelle s'impose l'inversion des positions sociales que réside tout l'intérêt - du pathos et de la violence qui caractérisaient l'issue de $L a$ Cérémonie (Claude Chabrol, 1995) ou de Blessures assassines (Jean-Pierre Denis, 2000), et ne s'encombre pas des relations charnelles que l'on trouve par exemple dans le court métrage Rachel du Suisse Frédéric Mermoud (2006).

2 Mais que reste-t-il ? Avant tout: un corps qui occupe ou déserte un lieu, au sens d'un territoire défini de la diégèse, mais également de l'espace du champ. Car la villa huppée où travaille Stéphanie s'oppose à l'appartement de cette dernière. Grâce au montage alterné en contrepoint et à un redoublement du crescendo s'instaure un rapport de vases communicants entre ces deux espaces : étouffant dans son logement miteux où elle est envahie par les connaissances de son ami, elle s'approprie la spacieuse villa vide, et investi également le champ des gros plans du film. Entre ces deux espaces, les attitudes sont rejouées comme dans un miroir - c'est d'ailleurs sur un plan de Stéphanie se regardant dans la glace, s'imaginant porter les boucles d'oreille de la propriétaire, que s'installe sa pleine occupation du champ visuel. La jeune femme ne peut accéder à sa salle de bain qu'occupe son ami et doit se contenter d'une servietteéponge déjà utilisée par ce dernier, alors que la propriétaire découvre en rentrant que sa femme de ménage se sert de sa baignoire ainsi que de son peignoir. Dans les deux cas, le tissu blanc est « souillé » par l'accaparement de l'intrus. 
3 Les implications du peignoir sont cependant bien plus conséquentes, puisqu'elles touchent à l'identité même de sa propriétaire : les initiales «SB » qui y figurent valent en effet autant pour l'avocate Suzanne Borgeat que pour sa femme de ménage qui, à coup de questions indiscrètes, s'immisce dans ce milieu bourgeois en vue de remplacer son aînée. Ce qui est surprenant dans La délogeuse, c'est la résistance somme toute minime de l'avocate, qui prend conscience de son insatisfaction et a tôt fait de quitter la villa avec ses valises. Précisons qu'elle n'est jamais montrée en présence de son époux - si ce n'est sur des photographies que Stéphanie époussette -, et bouscule d'ellemême la régularité de son quotidien en se mettant en retard ou en rentrant plus tôt.

4 En fait, sous les dehors d'un duel entre les deux femmes, ce sont plutôt deux vies possibles qui se croisent et s'échangent à l'occasion d'une période de crise que traverse la bourgeoise. Peut-être plus décidée que résignée, Suzanne abandonne son mode de vie à celle qui semble vouloir l'embrasser, signifiant verbalement ce bouleversement par le registre vulgaire (elle qualifie son adversaire de "salope»). Stéphanie qui avait commencé par dérober une pomme dans une coupe - faute originelle s'il en est - fait sien ce luxe dont elle rêvait. Mais lorsque le mari de Suzanne rentre à la maison, traverse le salon occupé par Stéphanie sans la remarquer puis s'adresse à elle comme s'il s'agissait de son épouse pour lui dire qu'il a noté sa nouvelle coiffure, ce n'est pas un sourire de satisfaction qui se peint sur le visage de celle qui pourrait se considérer victorieuse, ainsi que le dernier plan nous laisse le temps de le comprendre: l'investissement des lieux s'accompagne nécessairement d'une appropriation des valeurs et habitus qui leur sont associés, et que Rouyet dépeint en creux au travers du constat posé de l'extérieur par un personnage intrusif.

La délogeuse (CH, 2008, 20').

Scénario et réalisation : Julien Rouyet.

Image : Patrick Tresch.

Montage: Mathilde de Romefort.

Son: Jason Page.

Interprètes : Julia Perazzini, Caroline Gasser,... 